\title{
Emisje hałasu w górnictwie nafty i gazu - kopalnie
}

\begin{abstract}
W artykule przedstawiono wyniki pomiarów hałasu środowiskowego towarzyszącego pracy urządzeń eksploatowanych w obiektach technologicznych kopalń gazu ziemnego i ropy naftowej oraz wyniki pomiarów ciśnienia akustycznego przeprowadzonych w celu wyznaczenia poziomów mocy akustycznych urządzeń stanowiących główne źródła hałasu w kopalniach. Wyznaczone poziomy mocy akustycznych wykorzystano do przeprowadzenia symulacji rozprzestrzeniania się hałasu w środowisku. Wartości poziomów emisji hałasu uzyskane na drodze symulacji porównano z wartościami pochodzącymi z bezpośrednich pomiarów hałasu środowiskowego, w punktach kontrolnych odpowiadających punktom pomiarowym.
\end{abstract}

Słowa kluczowe: hałas, wiertnia, poziom mocy akustycznej.

\section{Noise emissions in oil and gas mining - mines}

The article presents the results of environmental noise measurements, accompanying the work of equipment operated in technological facilities of natural oil and gas mines and the results of sound pressure level measurements, conducted to determine the sound power levels of the devices that are the predominant sources of noise in the mines.

Key words: noise, drilling, sound power level.

\section{Wprowadzenie}

Źródłami hałasu mogącymi powodować zmiany klimatu akustycznego w sąsiedztwie obiektów technologicznych kopalń ropy naftowej i gazu ziemnego są przede wszystkim kopalniane tłocznie gazu, stacje redukcyjno-pomiarowe, agregaty prądotwórcze, pompy dozujące i kotłownie. Większość tych urządzeń pracuje wewnątrz budynków lub w kontenerach, których zadaniem jest ograniczenie hałasu przedostającego się do środowiska. Poza urządzeniami mechanicznymi źródłem ciągłego ustalonego hałasu jest przepływ gazu przez odcinki instalacji (rurociągi, zwężki itp.). Hałas towarzyszy również pracy zaworów bezpieczeństwa, a także okresowo wykonywanym na odwiertach zabiegom specjalnym, np. syfonowaniu odwiertów [2].

Poziom hałasu emitowanego z obiektów technologicznych kopalń ropy i gazu uzależniony jest przede wszystkim od parametrów akustycznych pracujących urządzeń. Stopień uciążliwości hałasowej, a więc zasięg rozprzestrzeniania się hałasu w środowisku jest wypadkową parametrów akustycznych poszczególnych urządzeń oraz liczby urządzeń stanowiących źródła hałasu. Zależy ponadto od zagospodarowania obiektu, a także od morfologii terenu otaczającego kopalnię i sposobu jego użytkowania.
Opracowujący raporty OOŚ pod kątem emisji hałasu, sporządzane na etapie koncepcji zagospodarowania nowych złóż, jak i modernizacji istniejących obiektów technologicznych, napotykają na trudności związane $\mathrm{z}$ brakiem informacji o parametrach akustycznych planowanych urządzeń i instalacji. Parametrem, który jest niezbędny przy określaniu wpływu na klimat akustyczny instalacji przemysłowych jest poziom mocy akustycznej. Znajomość poziomu mocy akustycznej jest również cenna przy ocenie oddziaływania na środowisko instalacji istniejących, w sytuacji gdy brak jest możliwości wykonania pomiaru bezpośredniego, np. gdy różnica poziomu hałasu przy pracującej instalacji a tłem jest mniejsza niż $3 \mathrm{~dB}[1,5]$.

Próba określenia poziomów mocy akustycznej urządzeń eksploatowanych w kopalniach ropy i gazu, które można byłoby wykorzystać na potrzeby modeli rozprzestrzeniania się hałasu, opracowywanych dla obiektów stosujących podobne lub wręcz analogiczne urządzenia, była jednym z celów badań opisanych w artykule. Badania obejmowały wykonanie pomiarów hałasu emitowanego do środowiska z kopalnianych obiektów technologicznych oraz wyznaczenie poziomów mocy akustycznej wytypowanych źródeł hałasu na 
podstawie pomiarów ciśnienia akustycznego metodą orientacyjną zgodnie z normą PN-EN ISO 3746:2011 [3]. Uzyskane wyniki posłużyły do przeprowadzenia symulacji rozprzestrzeniania się hałasu w środowisku i następnie porównania wartości poziomów emisji hałasu uzyskanych z bezpośrednich pomiarów z wartościami poziomów emisji obliczonymi w programie IMMI, przy uwzględnieniu wyzna- czonych poziomów mocy akustycznych. Zastosowana metoda porównawcza pozwoliła również na określenie poziomów mocy akustycznych urządzeń, dla których nie było możliwości wykonania pomiarów ciśnienia akustycznego, poprzez dobór poziomu mocy akustycznej i tym samym dopasowanie wartości poziomów emisji z symulacji do uzyskanych z pomiarów.

\section{Badania poziomu hałasu emitowanego do środowiska}

Pomiary hałasu będącego wynikiem pracy urządzeń i instalacji wykonano metodą rejestracji elementarnych próbek hałasu, zgodnie z metodyką referencyjną opisaną w rozporządzeniu Ministra Środowiska z dnia 30 października 2014 r. w sprawie wymagań w zakresie prowadzenia pomiarów wielkości emisji oraz pomiarów ilości pobieranej wody [5]. Pomiary przeprowadzono w punktach pomiarowych wyznaczonych na granicach terenu badanych obiektów oraz w najbliższej okolicy, w tym na terenach podlegających ochronie (terenach z zabudową mieszkalną). Z uwagi na brak możliwości wykonania pomiarów tła akustycznego przy wyłączonych źródłach hałasu, badania tła wykonano w miejscach porównywalnych do punktów pomiarów hałasu emitowanego wskutek równoczesnej pracy wszystkich urządzeń na terenie badanego obiektu.
Wielkościami mierzonymi był równoważny poziom dźwię$\mathrm{ku} \mathrm{A}\left(L_{\text {Aeq }}\right)$ emitowanego do środowiska w wyniku równoczesnej pracy wszystkich urządzeń stanowiących źródła hałasu w danym obiekcie. Pomiary wykonano w punktach pomiarowych wyznaczonych na granicach działek badanych obiektów technologicznych oraz w ich sąsiedztwie, ze szczególnym uwzględnieniem terenów podlegających ochronie określonych w rozporządzeniu w sprawie dopuszczalnych poziomów hałasu w środowisku [4], które znajdują się najbliżej badanego obiektu. Na podstawie przeprowadzonych pomiarów elementarnych próbek hałasu wyznaczono średni poziom dźwię$\mathrm{ku}\left(L_{A s r}\right)$, a następnie obliczono poziom emisji hałasu w środowisku $\left(L_{A e k}\right)$. Współrzędne punktów pomiarowych wraz z obliczonymi wartościami $L_{\text {Aek }}$ przedstawiono w tablicy 1.

\section{Wyznaczenie poziomu mocy akustycznej na podstawie pomiarów ciśnienia akustycznego}

Pomiary ciśnienia akustycznego wytypowanych do badań urządzeń w celu wyznaczenia poziomu mocy akustycznej wykonano metodą orientacyjną, opisaną w normie PN-EN ISO 3746:2011 [3]. Pomiar metodą orientacyjną wykonuje się w warunkach przybliżonych do akustycznego pola swobodnego nad płaszczyzną odbijającą dźwięk, tj. w przestrzeni pomiarowej z jedną lub kilkoma płaszczyznami odbijającymi dźwięk. Warunki te występują w przestrzeni otwartej lub w dużym pomieszczeniu. Typ i wielkość urządzenia nie stanowią ograniczeń w zakresie stosowania metody orientacyjnej w przestrzeni otwartej. Pomiary mogą być także wykonywane w pomieszczeniach, gdzie urządzenia są zainstalowane i normalnie pracują [1]. Metody orientacyjne są szczególnie przydatne w przypadku występowania wysokiego poziomu tła oraz odbić. Zgodnie z normą do określenia mocy akustycznej źródeł hałasu na podstawie pomiarów ciśnienia akustycznego metodą orientacyjną można stosować dwa rodzaje powierzchni pomiarowych nad płaszczyzną odbijającą dźwięk: półkolistą lub prostopadłościenną [3]. Norma zaleca, aby pomiary przeprowadzać całkującym miernikiem poziomu dźwięku, spełniającym co najmniej wymagania klasy dokładności 2.
Mierzonymi wielkościami są uśrednione poziomy ciśnienia akustycznego podczas działania badanego źródła, a także poziom tła akustycznego. W każdym z punktów wyznaczonych na powierzchni pomiarowej, wykonuje się podczas pracy badanego źródła minimum trzy pomiary dźwięku A, $L_{p A i}^{I}$, a ich wartości uśrednia. Czas obserwacji powinien wynosić nie mniej niż 30 s. Kolejnym krokiem jest wyznaczenie poziomu dźwięku A, $L_{p A}^{I I}$ hałasu tła.

Wielkościami obliczanymi są poziomy mocy akustycznej badanego źródła hałasu. Przy obliczaniu poziomu mocy akustycznej należy uwzględnić wyznaczone poprawki, uwzględniające hałas tła $K_{1 A}$ oraz uwzględniające środowisko badawcze $K_{2 A}$.

Pomiary hałasu emitowanego do środowiska oraz pomiary ciśnienia akustycznego wytypowanych urządzeń wykonano w KGZ Kościan-Brońsko. Miernikiem zastosowanym w badaniach był całkujący miernik poziomu dźwięku Bruel \& Kjaer typ 2250 wraz z kalibratorem akustycznym Bruel \& Kjaer typ 4231. Urządzenia pomiarowe spełniają wymagania klasy dokładności 1. Opisane w niniejszym artykule badania przeprowadzono z zastosowaniem prostopadłościennej powierzchni pomiarowej. 


\section{Wyniki pomiarów hałasu środowiskowego}

Głównymi źródłami emisji hałasu do środowiska z terenu Kopalni Gazu Ziemnego Kościan-Brońsko są:

- trzy silniki pompowe tłoczni gazu znajdujące się w oddzielnych budynkach,

- pompy tłoczenia glikolu znajdujące się w kontenerze regeneracji TEG-u,

- przepływ turbulentny gazu przez instalację, w tym głównie przez zwężki redukcyjno-pomiarowe oraz instalację ODL,

- agregat prądotwórczy, rezerwowy - w trakcie pomiarów nie pracuje.

Poziom emisji hałasu z instalacji KGZ Kościan-Brońsko przedstawiono w tablicy 1 oraz na rysunku 1 .

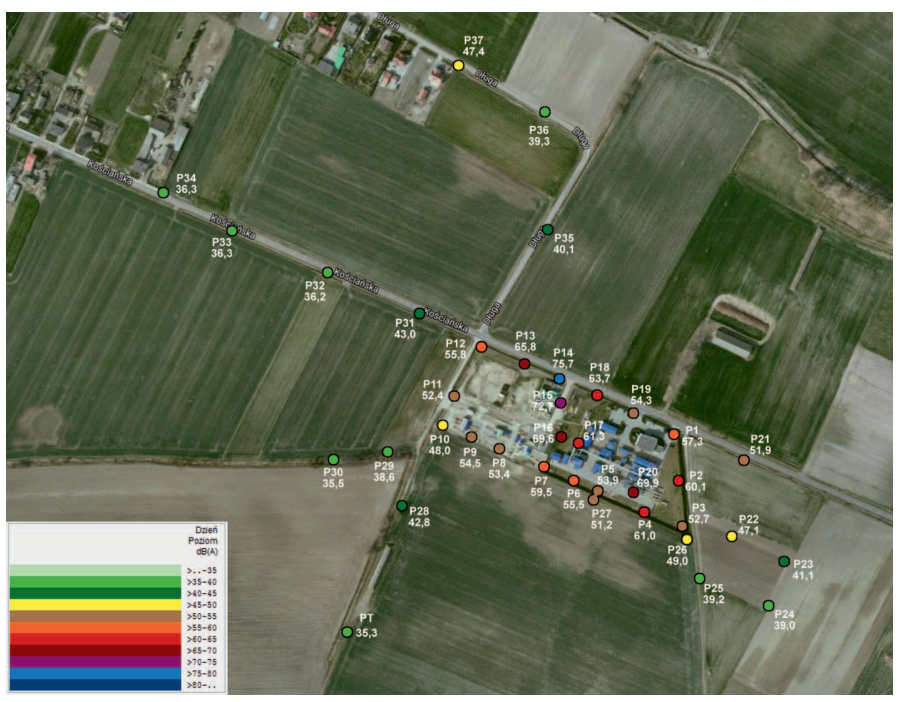

Rys. 1. Poziomy emisji hałasu w punktach pomiarowych na terenie i w sąsiedztwie KGZ Kościan-Brońsko

Tablica 1. Wyniki pomiarów poziomu emisji hałasu z KGZ Kościan-Brońsko

\begin{tabular}{|c|c|c|c|c|c|c|c|}
\hline \multirow{2}{*}{$\begin{array}{l}\text { Oznaczenie } \\
\text { punktu } \\
\text { pomiarowego }\end{array}$} & \multicolumn{2}{|c|}{ Współrzędne geograficzne } & \multirow{2}{*}{$\begin{array}{c}\text { Poziom emisji } \\
\text { hałasu } L_{A e k} \\
{[\mathrm{~dB}]}\end{array}$} & \multirow{2}{*}{$\begin{array}{l}\text { Oznaczenie } \\
\text { punktu } \\
\text { pomiarowego }\end{array}$} & \multicolumn{2}{|c|}{ Współrzędne geograficzne } & \multirow{2}{*}{$\begin{array}{c}\text { Poziom emisji } \\
\text { hałasu } L_{A e k} \\
{[\mathrm{~dB}]}\end{array}$} \\
\hline & szerokość & długość & & & szerokość & długość & \\
\hline $\mathrm{P} 1$ & 52,08509 & 16,59323 & 57,3 & P20 & 52,08457 & 16,59258 & 69,9 \\
\hline $\mathrm{P} 2$ & 52,08466 & 16,59327 & 60,1 & $\mathrm{P} 21$ & 52,08484 & 16,59413 & 51,9 \\
\hline P3 & 52,08422 & 16,59377 & 52,7 & P22 & 52,08417 & 16,59399 & 47,1 \\
\hline $\mathrm{P} 4$ & 52,08440 & 16,59270 & 61,0 & $\mathrm{P} 23$ & 52,08393 & 16,59482 & 41,1 \\
\hline P5 & 52,08455 & 16,59209 & 53,9 & P24 & 52,08352 & 16,59457 & 39,0 \\
\hline P6 & 52,08465 & 16,59174 & 55,5 & P25 & 52,08377 & 16,59354 & 39,2 \\
\hline P7 & 52,08477 & 16,59133 & 59,5 & P26 & 52,08413 & 16,59340 & 49,0 \\
\hline P8 & 52,08492 & 16,59065 & 53,4 & P27 & 52,08451 & 16,59199 & 51,2 \\
\hline P9 & 52,08502 & 16,59025 & 54,5 & $\mathrm{P} 28$ & 52,08440 & 16,58919 & 42,8 \\
\hline P10 & 52,08516 & 16,58980 & 48,0 & P29 & 52,08491 & 16,58899 & 38,6 \\
\hline P11 & 52,08539 & 16,58995 & 52,4 & P30 & 52,08483 & 16,58822 & 35,5 \\
\hline P12 & 52,08588 & 16,59037 & 55,8 & P31 & 52,08616 & 16,58949 & 43,0 \\
\hline P13 & 52,08570 & 16,59107 & 65,8 & P32 & 52,08653 & 16,58816 & 36,2 \\
\hline P14 & 52,08558 & 16,59155 & 75,7 & P33 & 52,08692 & 16,58678 & 36,3 \\
\hline P15 & 52,08538 & 16,59152 & 72,7 & P34 & 52,08723 & 16,58574 & 36,3 \\
\hline P16 & 52,08505 & 16,59158 & 69,6 & P35 & 52,08691 & 16,59131 & 40,1 \\
\hline P17 & 52,08497 & 16,59177 & 61,3 & P36 & 52,08796 & 16,59133 & 39,3 \\
\hline P18 & 52,08540 & 16,59211 & 63,7 & P37 & 52,08839 & 16,59005 & 47,4 \\
\hline P19 & 52,08526 & 16,59260 & 54,3 & & & & \\
\hline
\end{tabular}

\section{Wyznaczenie poziomu mocy akustycznej na podstawie pomiarów ciśnienia akustycznego}

W pomiarach, których celem było wyznaczenie poziomów mocy akustycznej źródeł hałasu w KGZ Kościan-Brońsko zastosowano, zgodnie z normą PN-EN ISO 3746, lokalizację punktów pomiarowych na prostopadłościennej powierzchni pomiarowej. Należy zaznaczyć, że metoda opisana ww. nor- mie jest metodą przybliżoną (orientacyjną) określania mocy akustycznej urządzenia.

W tablicy 2 i 3 przedstawiono wyniki pomiarów ciśnienia akustycznego pompy glikolu oraz silników napędowych tłoczni gazu w KGZ Kościan-Brońsko. 
Tablica 2. Poziom mocy akustycznej - pompy tłoczenia glikolu; KGZ Kościan-Brońsko

\begin{tabular}{|c|c|}
\hline Typ urządzenia & POMPY TŁOCZENIA GLIKOLU \\
\hline Lokalizacja urządzenia & Kopalnia Gazu Ziemnego Kościan-Brońsko \\
\hline \multicolumn{2}{|c|}{ ZMIERZONE ORAZ PRZYJĘTE PARAMETRY DO OBLICZENIA POZIOMU MOCY AKUSTYCZNEJ URZĄDZENIA } \\
\hline Wymiary prostopadłościanu odniesienia & $\begin{array}{l}l_{1}=7,0 \mathrm{~m} \\
l_{2}=1,5 \mathrm{~m} \\
l_{3}=1,0 \mathrm{~m}\end{array}$ \\
\hline $\begin{array}{l}\text { Odległość powierzchni pomiarowej od prostopadło- } \\
\text { ścianu odniesienia }\end{array}$ & $d=1,0 \mathrm{~m}$ \\
\hline $\begin{array}{l}\text { Wyniki pomiarów w punktach zlokalizowanych na } \\
\text { prostopadłościanie odniesienia }\end{array}$ & $\begin{array}{l}L_{p A 1}^{I}=79,1 \mathrm{~dB} \\
L_{p A 2}^{I}=79,5 \mathrm{~dB} \\
L_{p A 3}^{I}=81,6 \mathrm{~dB} \\
L_{p A 4}^{I}=81,1 \mathrm{~dB} \\
L_{p A 5}^{I}=79,3 \mathrm{~dB} \\
L_{p A 6}^{I}=79,3 \mathrm{~dB} \\
L_{p A 7}^{I}=81,1 \mathrm{~dB} \\
L_{p A 8}^{I}=81,0 \mathrm{~dB}\end{array}$ \\
\hline $\begin{array}{l}\text { Wyniki pomiarów tła w punktach zlokalizowanych na } \\
\text { prostopadłościanie odniesienia }\end{array}$ & $\begin{array}{l}\text { Ze względu na brak możliwości zatrzymania urządzenia w trakcie wykonywania po- } \\
\text { miarów, przyjęto, że tło akustyczne jest proporcjonalne do wyników pomiaru hałasu } \\
\text { na terenie KGZ. Przyjęto wartość } L_{p A}^{I I}=55 \mathrm{~dB}\end{array}$ \\
\hline Współczynnik pochłaniania dźwięku $\alpha$ & $\begin{array}{c}\text { Przyjęto współczynnik dźwięku } \alpha=0,15 \text {, jak dla pomieszczeń umeblowanych } \\
\text { o kształcie prostopadłościanu; maszynowni lub pomieszczeń przemysłowych } \\
\text { o kształcie prostopadłościanu }\end{array}$ \\
\hline Wymiary pomieszczenia & $\begin{array}{l}\text { Wymiary pomieszczenia, w jakim znajduje się urządzenie wynoszą: } \\
\qquad \begin{array}{l}\mathrm{a}=10,0 \mathrm{~m} \\
\mathrm{~b}=6,0 \mathrm{~m} \\
\mathrm{c}=3,0 \mathrm{~m}\end{array}\end{array}$ \\
\hline \multicolumn{2}{|c|}{ WYZNACZONY POZIOM MOCY AKUSTYCZNEJ URZĄDZENIA $\boldsymbol{L}_{W A}=\mathbf{9 8 , 4} \mathbf{d B}$} \\
\hline
\end{tabular}

Tablica 3. Poziom mocy akustycznej - silniki napędowe tłoczni gazu; KGZ Kościan-Brońsko

\begin{tabular}{|c|c|}
\hline Typ urządzenia & SILNIKI NAPĘDOWE TŁOCZNI GAZU \\
\hline Lokalizacja urządzenia & Kopalnia Gazu Ziemnego Kościan-Brońsko \\
\hline \multicolumn{2}{|c|}{ ZMIERZONE ORAZ PRZYJĘTE PARAMETRY DO OBLICZENIA POZIOMU MOCY AKUSTYCZNEJ URZĄDZENIA } \\
\hline Wymiary prostopadłościanu odniesienia & $\begin{array}{l}l_{1}=10,0 \mathrm{~m} \\
l_{2}=4,0 \mathrm{~m} \\
l_{3}=2,5 \mathrm{~m}\end{array}$ \\
\hline $\begin{array}{l}\text { Odległość powierzchni pomiarowej od prostopadło- } \\
\text { ścianu odniesienia }\end{array}$ & $d=1,0 \mathrm{~m}$ \\
\hline $\begin{array}{l}\text { Wyniki pomiarów w punktach zlokalizowanych na } \\
\text { prostopadłościanie odniesienia }\end{array}$ & $\begin{aligned} L_{p A 1}^{I} & =102,9 \\
L_{p A 2}^{I} & =102,6 \\
L_{p A 3}^{I} & =102,8 \\
L_{p A 4}^{I} & =100,8 \\
L_{p A 5}^{I} & =102,2 \\
L_{p A 6}^{I} & =102,3 \\
L_{p A 7}^{I} & =102,2 \\
L_{p A 8}^{I} & =102,8 \\
L_{p A 9}^{I} & =102,6 \\
L_{p A 10}^{I} & =102,3\end{aligned}$ \\
\hline $\begin{array}{l}\text { Wyniki pomiarów tła w punktach zlokalizowanych na } \\
\text { prostopadłościanie odniesienia }\end{array}$ & $\begin{array}{c}\text { Ze względu na brak możliwości zatrzymania urządzeń w trakcie wykonywania po- } \\
\text { miarów, przyjęto, że tło akustyczne jest proporcjonalne do wyników pomiaru hałasu } \\
\text { na zewnątrz budynku. Przyjęto wartość } L_{p A}^{I I}=55 \mathrm{~dB}\end{array}$ \\
\hline Współczynnik pochłaniania dźwięku $\alpha$ & $\begin{array}{c}\text { Przyjęto współczynnik dźwięku } \alpha=0,15 \text {, jak dla pomieszczeń umeblowanych } \\
\text { o kształcie prostopadłościanu; maszynowni lub pomieszczeń przemysłowych } \\
\text { o kształcie prostopadłościanu }\end{array}$ \\
\hline Wymiary pomieszczenia & $\begin{array}{l}\text { Wymiary pomieszczenia, w jakim znajduje się urządzenie wynoszą: } \\
\qquad \begin{array}{c}\mathrm{a}=12,0 \mathrm{~m} \\
\mathrm{~b}=8,0 \mathrm{~m} \\
\mathrm{c}=8,0 \mathrm{~m}\end{array}\end{array}$ \\
\hline \multicolumn{2}{|c|}{ WYZNACZONY POZIOM MOCY AKUSTYCZNEJ URZĄDZENIA $\boldsymbol{L}_{W A}=\mathbf{1 2 4 , 3} \mathbf{d B}$} \\
\hline
\end{tabular}




\section{Symulacje komputerowe rozprzestrzeniania się hałasu w środowisku}

Wykorzystując program IMMI do prognozowania i obliczeń rozprzestrzeniania się hałasu w środowisku, przeprowadzono symulacje, które pozwoliły na porównanie wartości poziomu emisji hałasu z instalacji KGZ Kościan-Brońsko, uzyskanych z pomiarów hałasu środowiskowego z wartościami poziomów emisji hałasu otrzymanymi z symulacji komputerowej, w której uwzględniono poziomy mocy akustycznych wyznaczone na podstawie pomiarów ciśnienia akustycznego.

Tablica 4. Wartości poziomów mocy akustycznej źródeł hałasu wyznaczone na podstawie pomiarów ciśnienia akustycznego metodą orientacyjną

\begin{tabular}{|l|c|}
\hline \multicolumn{1}{|c|}{ Urządzenie } & $\begin{array}{c}\text { Poziom mocy } \\
\text { akustycznej } L_{W A} \\
{[\mathrm{~dB}]}\end{array}$ \\
\hline Pompy tłoczenia glikolu & 98,4 \\
\hline $\begin{array}{l}\text { Agregat sprężarkowy - silniki napędowe } \\
\text { tłoczni gazu }\end{array}$ & 124,3 \\
\hline
\end{tabular}

Tablica 5. Wartości poziomów mocy akustycznej źródeł hałasu otrzymane na podstawie symulacji w programie IMMI

\begin{tabular}{|l|c|}
\hline \multicolumn{1}{|c|}{ Urządzenie } & $\begin{array}{c}\text { Poziom mocy } \\
\text { akustycznej } L_{W A} \\
{[\mathrm{~dB}]}\end{array}$ \\
\hline Instalacja ODL & 84,0 \\
\hline
\end{tabular}

W trakcie wykonywania pomiarów oddziaływania instalacji na klimat akustyczny poziom dźwięku zmierzono w 37 punktach.

Do symulacji przyjęto wartości poziomów mocy akustycznych wyznaczone na podstawie pomiarów ciśnienia akustycznego urządzeń przedstawionych w tablicy 4.

Na podstawie symulacji określono poziom mocy akustycznej urządzeń, dla których nie było możliwe wykonanie pomiarów

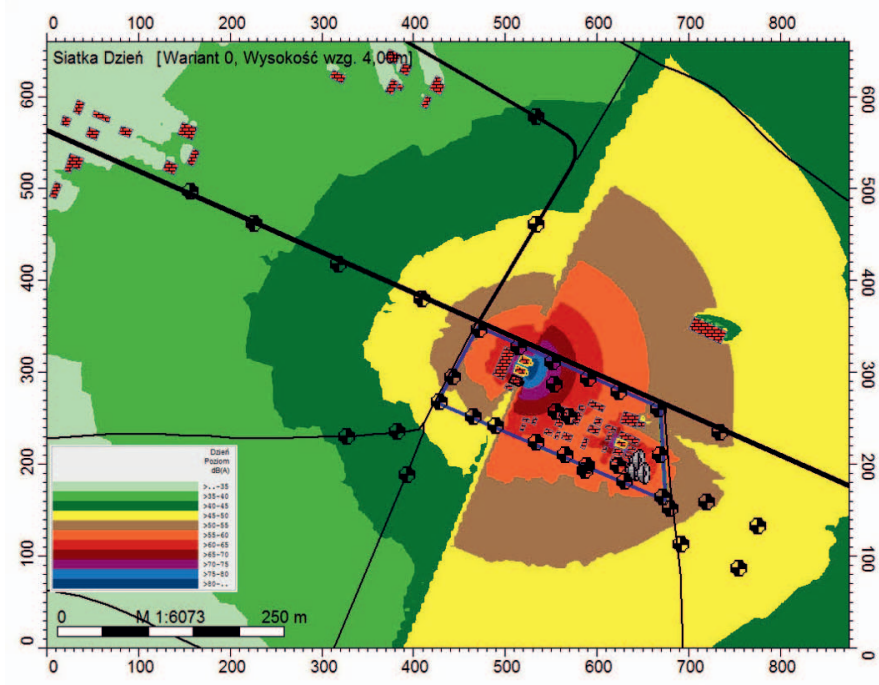

Rys. 2. Symulacja rozprzestrzeniania się hałasu wokół KGZ Kościan-Brońsko

Tablica 6. Porównanie poziomów emisji hałasu uzyskanych z pomiarów hałasu środowiskowego $\mathrm{z}$ poziomami emisji hałasu $\mathrm{z}$ symulacji opartych o wyznaczone poziomy mocy akustycznej

\begin{tabular}{|c|c|c|c|c|c|c|c|}
\hline \multirow{2}{*}{$\begin{array}{l}\text { Oznaczenie } \\
\text { punktu } \\
\text { pomiarowego }\end{array}$} & $\begin{array}{l}\text { Poziom emisji } \\
\text { hałasu - wartość } \\
\text { zmierzona }\end{array}$ & $\begin{array}{l}\text { Poziom } \\
\text { emisji hałasu } \\
\text { - symulacja }\end{array}$ & Różnica & \multirow{2}{*}{$\begin{array}{l}\text { Oznaczenie } \\
\text { punktu } \\
\text { pomiarowego }\end{array}$} & $\begin{array}{l}\text { Poziom emisji } \\
\text { hałasu - wartość } \\
\text { zmierzona }\end{array}$ & $\begin{array}{l}\text { Poziom } \\
\text { emisji hałasu } \\
\text { - symulacja }\end{array}$ & Różnica \\
\hline & $L_{A e k}[\mathrm{~dB}]$ & {$[\mathrm{dB}]$} & {$[\mathrm{dB}]$} & & $L_{A e k}[\mathrm{~dB}]$ & {$[\mathrm{dB}]$} & [dB] \\
\hline $\mathrm{P} 1$ & 57,3 & 54,3 & $-3,0$ & P19 & 54,3 & 58,1 & 3,8 \\
\hline $\mathrm{P} 2$ & 60,1 & 58,4 & $-1,7$ & P20 & 69,9 & 58,0 & $-11,9$ \\
\hline P3 & 52,7 & 51,9 & $-0,8$ & P21 & 51,9 & 50,8 & $-1,1$ \\
\hline $\mathrm{P} 4$ & 61,0 & 57,2 & $-3,8$ & P22 & 47,1 & 50,7 & 3,6 \\
\hline $\mathrm{P} 5$ & 53,9 & 53,9 & 0,0 & $\mathrm{P} 23$ & 41,1 & 48,1 & 7,0 \\
\hline P6 & 55,5 & 56,6 & 1,1 & P24 & 39,0 & 46,8 & 7,8 \\
\hline $\mathrm{P} 7$ & 59,5 & 57,8 & $-1,7$ & $\mathrm{P} 25$ & 39,2 & 48,7 & 9,5 \\
\hline P8 & 53,4 & 53,0 & $-0,4$ & P26 & 49,0 & 50,4 & 1,4 \\
\hline P9 & 54,5 & 50,4 & $-4,1$ & P27 & 51,2 & 54,6 & 3,4 \\
\hline P10 & 48,0 & 48,6 & 0,6 & P28 & 42,8 & 43,5 & 0,7 \\
\hline P11 & 52,4 & 52,2 & $-0,2$ & P29 & 38,6 & 44,4 & 5,8 \\
\hline P12 & 55,8 & 55,2 & $-0,6$ & P30 & 35,5 & 42,1 & 6,6 \\
\hline P13 & 65,8 & 68,5 & 2,7 & P31 & 43,0 & 47,3 & 4,3 \\
\hline P14 & 75,7 & 72,5 & $-3,2$ & P32 & 36,2 & 42,6 & 6,4 \\
\hline $\mathrm{P} 15$ & 72,7 & 69,6 & $-3,1$ & P33 & 36,3 & 39,1 & 2,8 \\
\hline P16 & 69,6 & 63,6 & $-6,0$ & P34 & 36,3 & 37,2 & 0,9 \\
\hline P17 & 61,3 & 50,9 & $-10,4$ & P35 & 40,1 & 47,6 & 7,5 \\
\hline P18 & 63,7 & 61,7 & $-2,0$ & P36 & 39,3 & 42,5 & 3,2 \\
\hline
\end{tabular}


ciśnienia akustycznego. Poprzez dobór poziomu mocy akustycznej i tym samym dopasowanie wartości poziomów emisji z symulacji do uzyskanych z pomiarów otrzymano poziom mocy akustycznej dla instalacji ODL równy 84,0 dB.

$\mathrm{W}$ tablicy 6 porównano wartości poziomu emisji hałasu z instalacji, uzyskane z pomiarów hałasu środowiskowego (po uwzględnieniu wpływu tła akustycznego) z wartościami poziomów emisji hałasu otrzymanymi z symulacji wykonanej w programie IMMI, w której uwzględniono poziomy mocy akustycznych uzyskane z pomiarów i dopasowania.

\section{Podsumowanie}

W wyniku symulacji rozprzestrzeniania się hałasu w środowisku, wykonanych przy pomocy programu IMMI z uwzględnieniem poziomów mocy akustycznych, wyznaczonych na podstawie pomiarów ciśnienia akustycznego metodą orientacyjną, uzyskano w wielu punktach kontrolnych wartości poziomu hałasu zbliżone do wartości zmierzonych. W sytuacji gdy nie dysponujemy poziomami mocy akustycznej źródła hałasu podanymi przez producenta, wyznaczone w ten sposób poziomy mocy akustycznej badanych urządzeń mogą być przydatne do celów prognozowania ich wpływu na klimat akustyczny, np. przy opracowywaniu raportów OOŚ pod kątem emisji hałasu. Należy jednak zauważyć, że same prognozy sporządzane na podstawie symulacji rozprzestrzeniania się hałasu w środowisku, niezależnie od tego czy będą oparte o parametr mocy akustycznej podany przez producenta, czy wy- znaczony na podstawie pomiarów in-situ urządzenia eksploatowanego na innym obiekcie, są zawsze obarczone pewnym błędem. W rezultacie uzyskane w drodze symulacji wartości poziomu emisji hałasu zawsze odbiegają od wartości rzeczywistych. Jest to spowodowane m.in. niemożliwością zdefiniowania i określenia charakterystyk akustycznych wszystkich stanowiących źródła hałasu urządzeń, których funkcjonowanie na terenie kopalni węglowodorów ma wpływ na sumaryczną emisję hałasu z danego obiektu technologicznego.

Różnice między pomierzonymi wartościami poziomów emisji hałasu a wartościami poziomów emisji, uzyskanymi z symulacji uwzględniającej poziomy mocy akustycznych wyznaczone na podstawie pomiarów ciśnienia akustycznego, wynikać mogą ponadto z zastosowanej orientacyjnej metody wyznaczania mocy akustycznej, posiadającej klasę dokładności 3.

Prosimy cytować jako: Nafta-Gaz 2018, nr 5, s. 380-385, DOI: 10.18668/NG.2018.05.05

Artykuł nadesłano do Redakcji 7.12.2017 r. Zatwierdzono do druku 9.03.2018 r.

Artykuł powstał na podstawie pracy statutowej pt.: Badania hałasu wraz z ocena oddziaływania na klimat akustyczny urzadzeń $i$ instalacji stosowanych w górnictwie nafty i gazu - praca INiG - PIB na zlecenie MNiSW; nr zlecenia: 0018/SN/17/01, nr archiwalny: DK-4100-5/17.

\section{Literatura}

[1] Nolepa A., Kiprian K., Siemiątkowski G., Łach P.: Metody wyznaczania poziomu mocy akustycznej źródta. Prace Instytutu Ceramiki i Materiałów Budowlanych 2015, nr 21, s. 43-57 (dostęp: 25.09.2017).

[2] Uliasz-Misiak B., Dubiel S.: Aspekty środowiskowe w zarzadzaniu złożem węglowodorów w fazie jego zagospodarowywania. Przegląd Górniczy 2015, nr 4, s. 56-62.

[3] Urba R.: Niepewność pomiaru fizykochemicznych czynników środowiskowych $w$ zakładach górnictwa nafty i gazu. Nafta-Gaz 2010, nr 7, s. 573-576.

[4] Urba R.: Zastosowanie narzędzi programistycznych do oceny hałasu wokół eksploatowanych wiertnic. Nafta-Gaz 2016, nr 2, s. 118-123, DOI: 10.18668/NG.2016.02.07.

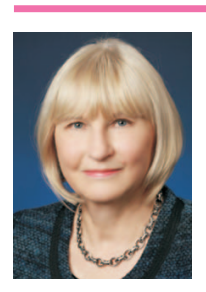

Mgr inż. Joanna ZALESKA-BARTOSZ

Starszy specjalista badawczo-techniczny w Zakładzie Ocen Środowiskowych.

Instytut Nafty i Gazu - Państwowy Instytut Badawczy

ul. Lubicz $25 \mathrm{~A}$

31-503 Kraków

E-mail: zaleska-bartosz@inig.pl

\section{Akty prawne i normatywne}

[5] PN-EN ISO 3746:2011 Akustyka - Wyznaczanie poziomów mocy akustycznej i poziomów energii akustycznej źródeł hałasu na podstawie pomiarów ciśnienia akustycznego. Metoda orientacyjna z zastosowaniem otaczajacej powierzchni pomiarowej nad płaszczyzna odbijająca dźwięk.

[6] Rozporządzenie Ministra Środowiska z dnia 14 czerwca 2007 r. w sprawie dopuszczalnych poziomów hałasu w środowisku (tekst jedn. Dz.U. z 2014 r., poz. 112).

[7] Rozporządzenie Ministra Środowiska z dnia 30 października 2014 r. w sprawie wymagań w zakresie prowadzenia pomiarów wielkości emisji oraz pomiarów ilości pobieranej wody (Dz.U. z 2014 r., poz. 1542).

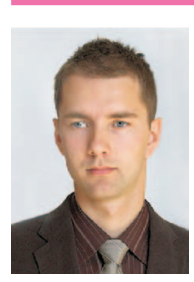

Mgr inż. Grzegorz KOŁODZIEJAK

Starszy specjalista inżynieryjno-techniczny w Zakładzie Ocen Środowiskowych.

Instytut Nafty i Gazu - Państwowy Instytut Badawczy ul. Lubicz 25 A

31-503 Kraków

E-mail: grzegorz.kolodziejak@inig.pl 